\title{
Family history of cancer and renal cell cancer risk in Caucasians and African Americans
}

\section{S Karami*,', K Schwartz², MP Purdue', FG Davis ${ }^{3}$, J Ruterbusch², SS Munuo ${ }^{4}$, S Wacholder', BI Graubard', JS Colt' and W-H Chow'}

'Division of Cancer Epidemiology and Genetics, National Cancer Institute, 6120 Executive Boulevard, MSC 7242, Bethesda, MD 20892-7242, USA; ${ }^{2}$ Karmanos Cancer Institute, Departments of Family Medicine and Public Health Sciences and Population Studies and Prevention Program, Wayne State University, 110 E. Warren, Detroit, MI 4820I, USA; ${ }^{3}$ Division of Epidemiology and Biostatistics, School of Public Health, University of Illinois, 877 SPHPI M/C 923, 1603 W. Taylor Street, Chicago, IL 606 I2, USA; ${ }^{4}$ Information Management Service Inc., 61 I0 Executive Blvd Suite no. 310 , Rockville, MD 20852, USA

BACKGROUND: The association between renal cell carcinoma (RCC) risk and family history of cancer has not been examined with an adequate number of African Americans (AAs).

METHODS: In a population-based case-control study, unconditional logistic regression was used to calculate the association between $\mathrm{RCC}$ risk and a family history of cancer among $1217 \mathrm{RCC}$ cases and 1235 controls.

RESULTS: Increased RCC risk was shown for subjects with at least one first-degree relative with kidney cancer (odds ratio = 2.29; $95 \%$ confidence interval $=1.31-4.00)$. No differences in risk were observed when analyses were stratified by race. For Caucasians, excess risk was observed among those reporting a sibling with kidney cancer, whereas for AAs, increased risk occurred among subjects reporting either a sibling or parent affected with the disease. A family history of non-renal cancers, and those related to smoking or to the von Hippel-Lindau syndrome, revealed no association with RCC risk.

CONCLUSION: The RCC risk associated with a family history of kidney cancer is similar among Caucasians and AAs.

British Journal of Cancer (2010) 102, 1676-1680. doi:I0.1038/sj.bjc.6605680 www.bjcancer.com

Published online 4 May 2010

(c) 2010 Cancer Research UK

Keywords: renal cancer; kidney cancer; family history of cancer; race; Blacks

In the United States, malignant tumours of the kidney account for nearly $4 \%$ of cancer diagnoses and $2 \%$ of cancer deaths (Jemal et al, 2009). Adenocarcinoma of the renal parenchyma (renal cell carcinoma (RCC)) is the most common form, accounting for more than $85 \%$ of kidney cancers (Chow and Devesa, 2008). Since 1950, in the United States, there has been a $126 \%$ increase in RCC incidence (Paglino et al, 2007), with higher rates reported among African Americans (AAs) than among Caucasians (Chow and Devesa, 2008). The increasing rates of RCC over time may reflect, in part, the increasing use of imaging modalities (Paglino et al, 2007; Chow and Devesa, 2008; Patard, 2009). However, as the increase involves all tumour sizes, not just those at the local stage (Patard, 2009), imaging modalities alone do not entirely explain the increase.

The aetiology of RCC is complex, with both environmental and hereditary components suspected to have a role. Smoking, obesity, and hypertension are primary risk factors that may explain half of all RCC diagnoses in the United States (Benichou et al, 1998; Chow and Devesa, 2008). RCC risk has been examined in relation to familial history of cancer in a number of epidemiological studies (McLaughlin et al, 1984; Kreiger et al, 1993; Goldgar et al, 1994; Mellemgaard et al, 1994; Schlehofer et al, 1996; Gago-Dominguez et al, 2001; Czene and Hemminki, 2002, 2003; Gudbjartsson et al, 2002; Negri et al, 2006;

*Correspondence: Dr S Karami; E-mail: karamis@mail.nih.gov Received 8 March 20I0; revised 8 April 20I0; accepted 9 April 20I0; published online 4 May 2010
Hung et al, 2007; Randi et al, 2007; Clague et al, 2009). Many of these studies have shown a positive association with a family history of cancer (Goldgar et al, 1994; Mellemgaard et al, 1994; Schlehofer et al, 1996; Gago-Dominguez et al, 2001), particularly when the affected relative is a sibling (Czene and Hemminki, 2002; Gudbjartsson et al, 2002; Negri et al, 2006; Hung et al, 2007; Clague et al, 2009).

Despite the racial disparity in RCC incidence, the numbers of AAs studied have been insufficient to examine their risk separately. In a recently completed population-based case-control study with a relatively large number of AA subjects, we examined whether RCC risk was elevated among participants with a history of cancer among first-degree relatives, and whether risk varied by race.

\section{MATERIALS AND METHODS}

This population-based case-control study was conducted in Chicago, IL, and in Detroit, MI. Cases were resident Caucasian and AA men and women, aged 20-79 years, newly diagnosed with RCC in Chicago from 1 January 2003 through to 31 December 2003 and in Detroit from 1 February 2002 through to 31 January 2007 for AAs and through to 31 July 2006 for Caucasians. All cases had histologically confirmed adenocarcinoma of the kidney (ICD-O C64). Controls selected from the general population were frequency matched to cases on age, race, sex, and study centre. Controls aged 65-79 years were identified from files of the Centers for Medicare and Medicaid Services, and controls under the age of 65 years were identified from the Department of Motor Vehicle (DMV) records. A sampling strategy was designed to increase the 
number of AA participants used for analyses. All AA cases were recruited, whereas some strata (age-race-sex combinations) of Caucasian cases were subsampled. Controls were frequency matched to cases at a 2:1 ratio for AAs and at a $1: 1$ ratio for Caucasians. As information on race was unavailable from DMV records, this hampered our ability to frequency match controls to cases among those 20-64 years of age. Therefore, we used the racial density of the census block group (according to the 2000 census), in which each control resided to serve as a surrogate for race for the purposes of sampling. We oversampled people living in high-density AA areas to help achieve the targeted matching ratios for AAs.

Of 1918 eligible cases identified, 171 died before contact or interview, 92 could not be located with the available contact information, 21 moved out of the area, and the physicians of 63 cases refused permission to contact their patients. Among the remaining 1571 cases we sought to enrol, 221 declined participation and 133 were not interviewed because of serious illness, impairment, or failure to respond to multiple attempts to contact. Thus, 1217 cases $(77.5 \%$ of those we attempted to recruit) participated in the study. Of 2718 presumed eligible controls, 41 died before contact or interview, 345 could not be located with the available contact information, and 63 had moved out of the region. Among the 2269 controls we attempted to recruit, 677 declined to participate and 357 were not interviewed because of serious illness, impairment, or failure to respond to multiple attempts to contact. Thus, 1235 eligible controls (54.4\% of those we attempted to recruit) participated. Institutional review board approvals were obtained from all participating study centres and informed written consent was obtained from all participants.

Trained interviewers were administered an in-home, computerassisted personal interview, in which detailed information was collected on demographics, smoking history, medical and medication history, diet, occupation, and family history of cancer. Information on family history of cancer was collected for all first-degree relatives (parent, sibling, and offspring), including cancer site and age at diagnosis. For analytical purposes, a set of sample weights were developed to reduce the potential for bias arising from differential sampling rates for controls and cases, from survey non-response, and from deficiencies in the coverage of the population at risk by the files of the DMV and Centers for Medicare and Medicaid Services to select controls. For controls, their sample weights also include a poststratification adjustment so that the weighted distribution of controls across the matching variables matches the weighted distribution of cases in an exact manner. In addition to being consistent with the objectives of frequency matching, this poststratification adjustment reduces the variability of the weights compared with not using this adjustment (Li et al, 2010).

The sample-weighted frequency distributions of selected characteristics and known RCC risk factors were compared between cases and controls using a Wald F-test. A $\chi^{2}$-test was also used to compare the unweighted sample distribution of selected characteristics in which similar findings were produced (data not shown). Unconditional logistic regression models using poststratified weights were used to calculate odds ratios (ORs) and $95 \%$ confidence intervals (95\% CIs) associated with a family history of kidney cancer and a family history of non-renal cancers, using subjects who did not have any family history of cancer as the reference group. The jackknife replicate weight method was used to estimate s.e. (Rust and Rao, 1996). Stratified analyses by race were conducted, and interactions with race and family history were tested using a $t$-test and a Wald test. Regression models were adjusted for age at reference date (age at diagnosis for cases and age at study selection for controls), sex, race, study centre, education level, hypertension history (ever, never), family size (defined as number of siblings and number of offspring), smoking status, and body mass index. Unweighted unconditional logistic regression analyses and tests for interactions comparing regression models with and without interaction terms were also calculated, in which results were similar to that of the weighted analysis (data not shown). All analyses were conducted with STATA software version 10.1 (StatCorp, 2007). Statistical tests were determined to be significant at a two-sided $P$-value $<0.05$.

\section{RESULTS}

Overall, cases and controls were comparable in sex and age distributions (Table 1). As expected, cases were more likely to smoke, have hypertension, and have an excess body weight (body mass index $\geqslant 30 \mathrm{~kg} \mathrm{~m}^{-2}$ ). Cases were more likely to have a lower education level than controls. Similar distributions of characteristics were observed when analyses were stratified by race.

A significant elevation in risk is shown in Table 2 among participants reporting at least one first-degree relative with kidney cancer $(\mathrm{OR}=2.29 ; 95 \% \mathrm{CI}=1.31-4.00)$. Analysis by relative type revealed a non-significant increase in risk $(\mathrm{OR}=1.45 ; 95 \% \mathrm{CI}=0.77-2.72)$ when the affected relative was a parent; however, a significant increase in risk was observed when a sibling was affected $(\mathrm{OR}=3.09 ; 95 \% \mathrm{CI}=1.33-7.20)$. Stratified analyses showed no consistent differences in these associations by race, although the estimated risk associated with a parent having had kidney cancer was stronger among AAs $(\mathrm{OR}=2.98 ; 95 \% \mathrm{CI}=1.06-8.37)$ than among Caucasians $(\mathrm{OR}=1.13 ; 95 \% \mathrm{CI}=0.50-2.58) \quad(P$-interaction $=0.19$ ). A family history of non-renal cancers among firstdegree relatives was not associated with RCC risk, regardless of whether family history was defined by relative type or stratified by race.

RCC risk was comparable whether one $(\mathrm{OR}=2.35 ; 95 \%$ $\mathrm{CI}=1.11-4.96)$ or more than one $(\mathrm{OR}=2.23 ; 95 \% \mathrm{CI}=1.02$ 4.88) first-degree relative was reported to have been diagnosed with kidney cancer. The findings were similar when family history of non-renal cancers was reported in one $(\mathrm{OR}=0.93 ; 95 \%$ $\mathrm{CI}=0.75-1.14)$ compared with more than one $(\mathrm{OR}=1.09 ; 95 \%$ $\mathrm{CI}=0.80-1.49)$ first-degree relative. No meaningful differences in risk were observed with regard to relative type or race (data not shown).

Because the von Hippel-Lindau syndrome is commonly linked to inherited RCC, we examined the relationship between RCC risk and a family history of several cancers that have been reported in families with this syndrome (cancers of the retina, spinal cord, brain stem, cerebellum, adrenal gland, pancreas, broad ligament, and endolymphatic sac of the inner ear) (Kaelin, 2008). No association was observed $(\mathrm{OR}=0.99 ; 95 \% \mathrm{CI}=0.74-1.32)$. A family history of smoking-related cancers (cancers of the lung, bladder, breast, cervix, colon, oesophagus, larynx, pancreas, stomach, oral cavity, and head and neck) was not related to RCC risk $(\mathrm{OR}=0.99 ; 95 \% \mathrm{CI}=0.83-1.19)$. No statistically significant interactions between a family history of kidney cancer and potential confounders (i.e., body mass index, age, sex, smoking status, and hypertension history) were detected (data not shown). No meaningful difference in association was revealed when analyses were restricted to cases diagnosed with the clear-cell subtype of RCC or with high-grade (Furhman nuclear grades III and IV) tumours (data not shown).

\section{DISCUSSION}

This study confirms an association between RCC risk and a family history of kidney cancer and, for the first time, shows that such risk is comparable among Caucasians and AAs in the United States. Among Caucasians, the excess risk was observed mainly in individuals who reported having a sibling with kidney cancer; among AAs, excess risk was seen whether the affected relative was a sibling or a parent. 
Table I Weighted characteristics of participants

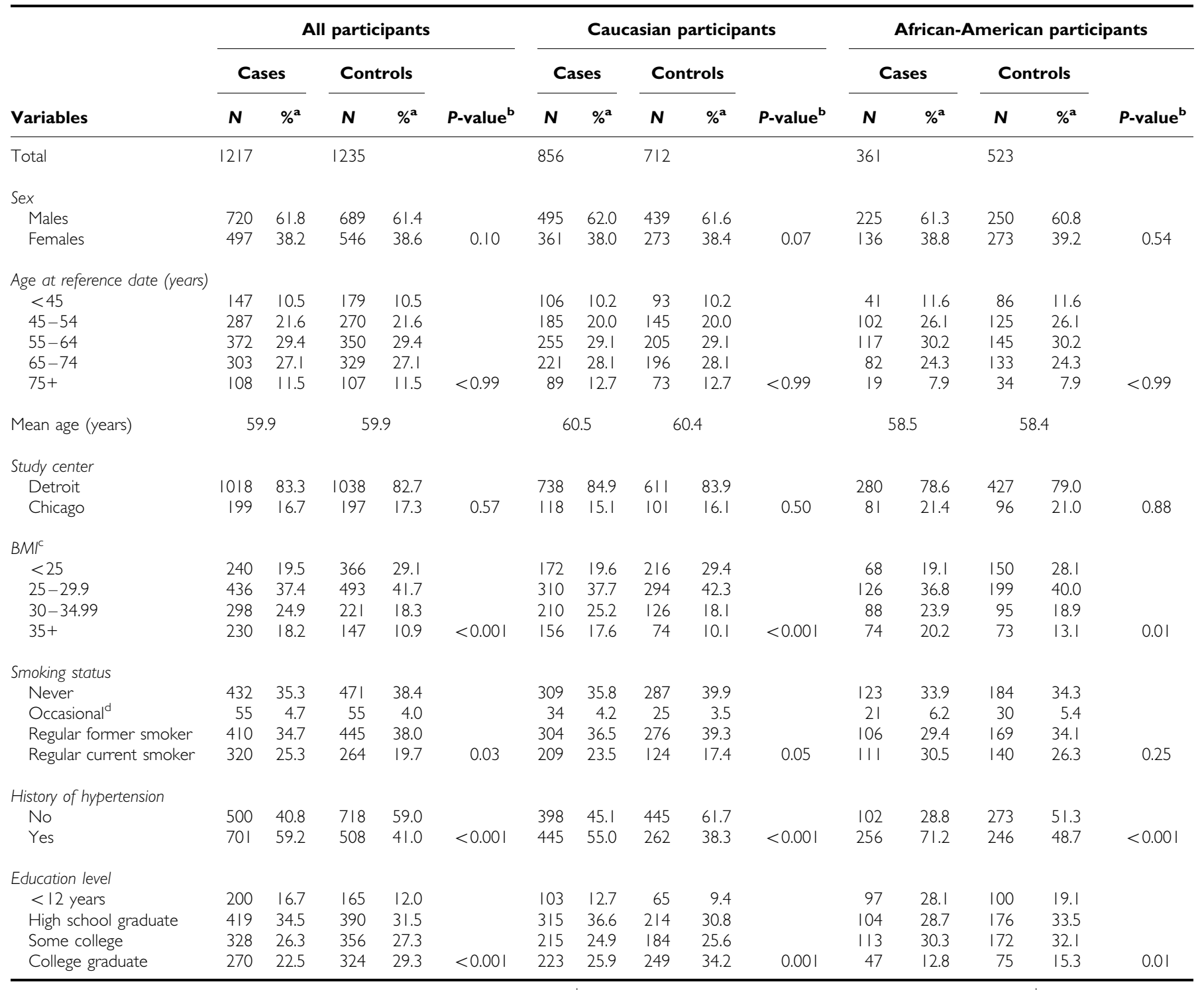

Abbreviation: BMI = body mass index. ${ }^{a}$ A sample-weighted frequency distribution. ${ }^{b}$-value from sample Wald F-test. ${ }^{c}$ BMI 5 years before interview. ${ }^{d}$ Smoked I00 cigarettes in the lifetime, but never smoked at least I cigarette a day for 6 months or longer. The following data are unknown: BMI (eight Caucasian cases, two Caucasian controls, five African-American cases, six African-American controls), history of hypertension (thirteen Caucasian cases, five Caucasian controls, three African-American cases, four African-American controls).

Increased risk of renal cancer has been associated with a family history of kidney cancer in most previous case-control (Mellemgaard et al, 1994; Schlehofer et al, 1996; Gago-Dominguez et al, 2001; Negri et al, 2006; Clague et al, 2009) and cohort studies (Goldgar et al, 1994; Czene and Hemminki, 2002; Gudbjartsson et al, 2002; Clague et al, 2009), although results for some are null or not statistically significant (McLaughlin et al, 1984; Kreiger et al, 1993; Hung et al, 2007; Randi et al, 2007). The reported excess risks generally ranged from two- to five-fold for both study designs. Most studies that have examined the type of first-degree relative with kidney cancer reported a stronger renal cancer risk if the affected relative was a sibling than a parent (Czene and Hemminki, 2002; Gudbjartsson et al, 2002; Negri et al, 2006; Hung et al, 2007). A recently published meta-analysis of seven case-control studies and three cohort studies reported an overall two-fold increase in RCC risk associated with a family history of kidney cancer, and the risk was nearly four-fold when the affected relative was a sibling (Clague et al, 2009). In this study, we also observed a greater risk with a reported history of kidney cancer in a sibling than in a parent, but this observation was confined to Caucasians. Because of the relatively small numbers of subjects with a family history of cancer, it is premature to conclude that there are racial differences in RCC risk by the type of first-degree relative affected with kidney cancer.

Elevated risk of sporadic RCC associated with a family history of kidney cancer may indicate an inherited component in aetiology or environmental exposures that are shared in families. Several genetic syndromes predisposing to familial RCC have been identified. The most common of the hereditary syndromes are germline mutations in the von Hippel-Lindau (VHL) tumoursuppressor gene on chromosome $3 \mathrm{p}$, which is associated exclusively with the clear cell histological subtype (Czene and Hemminki, 2002; Hung et al, 2007; Chow and Devesa, 2008). In addition to RCC, individuals with this germline mutation are at an increased risk for developing tumours of the central nervous system, retina, endolymphatic sac of the inner ear, broad ligament, 
Table 2 Family history of cancer and risk of renal cell carcinoma, stratified by race

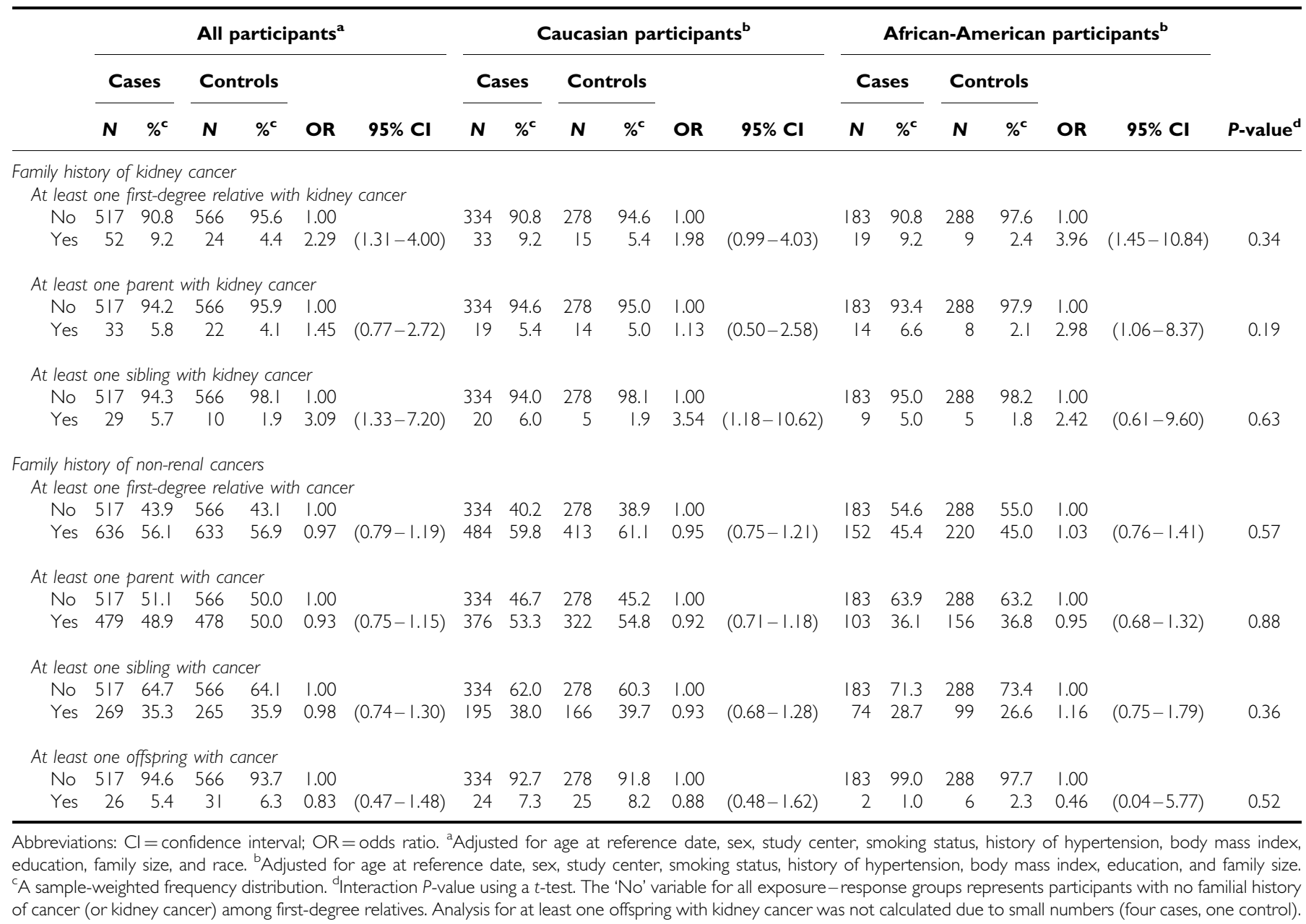

adrenal glands, and pancreas (Kaelin, 2008). However, we did not observe an association with a history of any of these VHL-related tumours among first-degree relatives. Shared environmental exposures among family members may also have a role in the associations observed in this study. We were unable to obtain exposure information for relatives of study participants or information on exposures during childhood; however, adjustment for known RCC risk factors, including smoking, obesity, and hypertension, did not modify the association between RCC risk and familial history of cancer. Until twin studies are conducted, it will be difficult to dissect the relative contributions of genetic factors and shared environmental exposures among family members on sporadic RCC risk. The largest published twin study has been uninformative on kidney cancer risk because of the lack of concordant twin pairs (Lichtenstein et al, 2000).

\section{REFERENCES}

Benichou J, Chow WH, McLaughlin JK, Mandel JS, Fraumeni Jr JF (1998) Population attributable risk of renal cell cancer in Minnesota. Am J Epidemiol 148: $424-430$

Chow WH, Devesa SS (2008) Contemporary epidemiology of renal cell cancer. Cancer J 14: 288-301

Clague J, Lin J, Cassidy A, Matin S, Tannir NM, Tamboli P, Wood CG, Wu X (2009) Family history and risk of renal cell carcinoma: results from a case-control study and systematic meta-analysis. Cancer Epidemiol Biomarkers Prev 18: $801-807$
This is the first RCC case-control study to include a sufficient number of AAs to evaluate their risks separately. Histologically confirmed cancer and a large sample size are strengths, but power for stratified analysis was limited. The response rate among controls was not optimal (54.4\%); however, the weighting strategies used in this study allowed for analyses that were more robust to nonresponse and the power for stratified analyses was limited. We did not verify the self-reported history of kidney cancer among firstdegree relatives, and recall may have been more accurate among cases than among controls. However, we believe this to be unlikely as no association with an increasing number of affected first-degree relatives with kidney cancer was observed.

This study finds that family history of kidney cancer among first-degree relatives is associated with a significantly increased RCC risk, and that risk is similar in Caucasians and AAs.

Czene K, Hemminki K (2002) Kidney cancer in the Swedish Family Cancer Database: familial risks and second primary malignancies. Kidney Int 61: $1806-1813$

Czene K, Hemminki K (2003) Familial papillary renal cell tumors and subsequent cancers: a nationwide epidemiological study from Sweden. J Urol 169: $1271-1275$

Gago-Dominguez M, Yuan JM, Castelao JE, Ross RK, Yu MC (2001) Family history and risk of renal cell carcinoma. Cancer Epidemiol Biomarkers Prev 10: 1001 - 1004 
Goldgar DE, Easton DF, Cannon-Albright LA, Skolnick MH (1994) Systematic population-based assessment of cancer risk in first-degree relatives of cancer probands. J Natl Cancer Inst 86: 1600-1608

Gudbjartsson T, Jónasdóttir TJ, Thoroddsen A, Einarsson GV, Jónsdóttir GM, Kristjánsson K, Hardarson S, Magnússon K, Gulcher J, Stefánsson K, Amundadóttir LT (2002) A population-based familial aggregation analysis indicates genetic contribution in a majority of renal cell carcinomas. Int $J$ Cancer 100: 476-479

Hung RJ, Moore L, Boffetta P, Feng BJ, Toro JR, Rothman N, Zaridze D, Navratilova M, Bencko V, Janout V, Kollarova H, Szeszenia-Dabrowska N, Mates D, Chow WH, Brennan P (2007) Family history and the risk of kidney cancer: a multicenter case-control study in Central Europe. Cancer Epidemiol Biomarkers Prev 16: $1287-1290$

Jemal A, Siegel R, Ward E, Hao Y, Xu J, Thun MJ (2009) Cancer Statistics, 2009. CA Cancer J Clin 59: 225-249

Kaelin Jr WG (2008) The von Hippel-Landau tumor suppressor protein: $\mathrm{O} 2$ sensing and cancer. Nat Rev Cancer 8: 865-873

Kreiger N, Marrett LD, Dodds L, Hilditch S, Darlington GA (1993) Risk factors for renal cell carcinoma: results of a population-based casecontrol study. Cancer Causes Controls 4: 101-110

Li Y, Graubard BI, DiGaetano R (2010) Weighting methods for populationbased case-control studies with complex sampling. J R Stat Soc Ser C (under revision)

Lichtenstein P, Holm N, Verkasalo P, Iliadou A, Kaprio J, Koskenvuo M, Pukkala E, Skytthe A, Hemminki K (2000) Environmental and heritable factors in causation of cancer. $N$ Engl J Med 343: 78-85
McLaughlin JK, Mandel JS, Blot WJ, Schuman LM, Mehl ES, Fraumeni Jr JF (1984) A population-based case-control study of renal cell carcinoma. J Natl Cancer Inst 72: 275-284

Mellemgaard A, Engholm G, McLaughlin JK, Olsen JH (1994) Risk factors for renal cell carcinoma in Denmark. I. Role of socioeconomic status, tobacco use, beverages, and family history. Cancer Causes Control 5: $105-113$

Negri E, Foschi R, Talamini R, Montella M, Ramazzotti V, Dal Maso L, Bosetti C, Franceschi S, Zucchetto A, La Vecchia C (2006) Family history of cancer and the risk of renal cell cancer. Cancer Epidemiol Biomarkers Prev 15: $2441-2444$

Paglino C, Imarisio I, Rovereto B (2007) Epidemiology, molecular epidemiology, and risk factors for renal cell carcinoma. Oncol Rev 1: $120-127$

Patard JJ (2009) Incidental renal tumours. Curr Opin Urol 19: 454-458

Randi G, Pelucchi C, Negri E, Talamini R, Galeone C, Franceschi S, La Vecchia C (2007) Family history of urogenital cancers in patients with bladder, renal cell and prostate cancers. Int J Cancer 121: 2748-2752

Rust KF, Rao JN (1996) Variance estimation for complex surveys using replication techniques. Stat Methods Med Res 5: 283-310

Schlehofer B, Pommer W, Mellemgaard A, Stewart JH, McCredie M, Niwa S, Lindblad P, Mandel JS, McLaughlin JK, Wahrendorf J (1996) International renal-cell-cancer study. VI. the role of medical and family history. Int J Cancer 66: $723-726$

StatCorp (2007) Stata Statistical Software: Release 10. StatCorp LP: College Station, TX 